\title{
Effect of High Intensity and Low Intensity Plyometric on Vertical Jump Height and Maximum Voluntary Isometric Contraction in Football Players
}

Shankar, R., Rajpal, H. and Arora, M.

Department of Physiotherapy, Sardar Bhagwan Singh (PG) Institute, Dehradun, Uttaranchal

\section{Abstract}

The study was conducted on 24 football players ranging between 21-32 years. The subjects were randomly divided into two groups and were named as high and low intensity plyometric groups. High intensity plyometric group was given exercises comprising of double and single leg vertical jumps alongwith single leg tuck jumps while low intensity plyometric group was administered split and cycled squat jumps. Both the groups were given plyometric training for four weeks. Vertical jump and maximum voluntary isometric contraction were recorded in both the groups at the start and $2^{\text {nd }}$ and $4^{\text {th }}$ week of training. In the present study, high intensity plyometric and low intensity plyometric exercises for four weeks showed different magnitudes of improvement in vertical jump height and maximal voluntary isometric contraction. Results of the study further show that High Intensity Plyometric training has significant effect on Vertical Jump Height and Maximum Voluntary Isometric Contraction as compared to Low Intensity Plyometric.

Key Words: Plyometric training, Football players, Vertical Jump, Maximum voluntary isometric contraction

\section{Introduction}

Because of the many benefits associated with sports success, athletes are always trying to improve their performances, usually under the guidance of skilled trainers, coaches and sports physiotherapists (Williams, 1997). Sports performance is reported to increase by combining various training methods (Siegler et al, 2003) and is limited by various factors such as inadequate energy production, poor energy control and poor energy efficiency (Williams, 1997). Supervised and periodized training has more potential for enhancing the performance and reducing the chances of injury in comparison with unsupervised and conventional training in various sports.
One of the most popular sports, played in every nation at varying levels of competence is Football. This is a multifactorial event which requires simultaneous attention on body size, body composition, strength, power, quickness, reaction time, speed, agility and endurance for better performance. Incorporation of strength training program has greatly improved strength and performance profiles of football players at all levels of competition (Willifor \& Kirpatrik, 1994). Boisseau et al (2007) has shown that the protein requirements of 14 year old male athletes are above the RDA for non-active male adolescents.

Studies have been reported which prove the effect of various training protocols in increasing the performance. 
Training for enhanced performance and injury prevention employ a variety of muscles training regimens including conventional training and plyometric training.

The eccentric utilization ratio (EUR), which is the ratio of countermovement jump to static jump performance, is suggested to be a useful indicator of power performance in athletes. Athletes in sports such as soccer, rugby have shown higher EUR values, which reflect the greater reliance on stretch shortening activities in these sports (Mcguigan et al, 2006). Plyometric training consists of a rapid stretching of a muscle (eccentric action) immediately followed by a concentric or shortening action of the same muscle and connective tissue (Baechle \& Earle, 2000). Plyometric drills usually involve stopping, starting, and changing direction in an explosive manner. Muscle under this condition is known to generate higher force and deliver greater energy than without a pre stretch. The main purpose of giving plyometric training is to increase the excitability of the nervous system for improved reactive ability of the neuromuscular system which is helpful in sports. Soccer player's performance is measured by testing jumping ability (Moore et al, 2005) and knee extensor torques (Kramer \& Balsor, 1990). Various training protocols have been formulated to measure the performance. It has been reported by Kramer \& Balsor (1990) that, to optimize jump performance it appears that athlete should not perform jump immediately following resistance training.

Plyometric exercises vary in both complexity and intensity. It should be taught and progressed accordingly.
Plyometric exercises are classified into four types, viz, low intensity, medium intensity, high intensity and shock exercises. High intensity plyometric is a vigorous, time taking, exhaustive training regime with a very rapid amortization phase in comparison to low intensity plyometric which is gentle and has a longer amortization phase. Low intensity exercises can produce the same effect being less exhaustive for the players and requiring less recovery time. Although plyometric training has been shown to increase performance variables like vertical jump and knee extensor strength and finally football performance, but no scientific information is available to determine the effect of high intensity and low intensity plyometric on football performance.

Therefore, the purpose of the study was to determine the efficacy of four weeks of high intensity versus low intensity plyometric exercises on vertical jump and knee extensor strength in football players.

\section{Materials and Methods}

A longitudinal experimental study was performed upon a total of 24 players with mean age of $21.05 \pm 1.32$ yrs, mean height of $1.70 \pm 0.027$ meters, mean weight of $63.95 \pm 1.99 \mathrm{~kg}$ and mean body mass index of $21.97 \pm 0.81$. The players were selected from 125 football players of Sardar Bhagwan Singh Post Graduate Institute (SBSPGI), Balawala, Dehradun after a homogenous random sampling. The subjects were given exercises at the sports ground of SBSPGI and the measurements were conducted at Research Laboratory of Physiotherapy Department of the institute. Only those subjects were included who had a previous history of playing football for 
one year and were not involved in plyometric exercises previously and possessed normal ROM at lumbar spine, hip, knee, ankle and a normal cardiorespiratory fitness level. Subjects were excluded if they had a history of fracture or suffered any pain during the regime or if they were irregular.

Subjects were asked to fill the consent form. Vertical jump height (VJH) and maximum voluntary isometric contraction was assessed at at the beginning of training i.e. zero week. Verbal instructions were given and the subjects were randomly separated into two groups on the basis of training administered, Group A being HIP (High Intensity Plyometric Group) and Group B being LIP (Low Intensity Plyometric Group). Each group did warm up exercises before the training regimen followed by a cool down session. Exercises were done three times a week for a span of 4 weeks. Measurements were then again taken at the end of $2^{\text {nd }}$ and $4^{\text {th }}$ week of training.

Vertical Jump Test (VJH) - The subjects were asked to stand erect with their dominant side next to the wall and foot flat. Chalk was given to the subject. He was instructed to reach as high as possible on the wall, with the highest point reached being marked and recorded. VJH was scored as a difference between the standing reach height and peak height achieved on jumping. Two readings were taken and an average was calculated.

Maximum Voluntary Isometric Contraction (MVIC) was tested for quadriceps muscle. The subject was made to sit on the quadriceps table with knees at 90 degree flexion and the strain gauge was attached to the subject's foot with the help of a chain. The subject was asked to contract the quadriceps muscle against the pull of the strain gauge attached behind. Three readings were taken and the average was calculated.

Plyometric exercise were given to both the groups A and B. High Intensity plyometric was given to Group A and Low Intensity plyometric was given to Group B.

Group A- High Intensity Plyometric

1. Double Leg Vertical Power Jump

2. Single Leg vertical Power Jump

3. Single Leg Tuck Jump

Group B- Low Intensity Plyometric

1. Split Squat Jump

2. Cycled Split Squat Jump

3. Squat Jump

All exercises were done 10 times. All the subjects were explained the exercises according to their groups. In Group A, two subjects were found to be irregular while coming to the field. Thus it being one of the exclusion criteria, these subjects were excluded from the study. In Group B one of the subjects discontinued during the first week and the second was injured during the practice match. The injury was diagnosed as anterior cruciate ligament injury. Thus both the players of Group B were excluded from the study.

\section{Results}

The data was analyzed. Unpaired $\mathrm{t}$ test was applied to vertical jump height and maximum voluntary isometric contraction between high intensity and low intensity plyometric groups.

Paired t test was applied within the group A and B each for the two variables - vertical jump height and maximum voluntary isometric contraction. 
The table given below is a descriptive status of the study.

\begin{tabular}{lcccc}
\hline & $\begin{array}{c}\text { High Intensity } \\
\text { Plyometric } \\
\text { Group }(\mathrm{N}=10)\end{array}$ & \multicolumn{2}{c}{$\begin{array}{c}\text { Low Intensity } \\
\text { Plyometric Group } \\
(\mathrm{N}=10)\end{array}$} \\
\hline Mean & SD & Mean & SD \\
Age (yrs) & 21.40 & 1.26 & 20.73 & 1.33 \\
VJH at 0 Wk & 34.65 & 5.01 & 31.92 & 6.30 \\
VJH at 2 Wk & 36.11 & 5.33 & 32.96 & 6.32 \\
VJH at 4 Wk & 38.21 & 5.23 & 33.90 & 6.36 \\
MVIC at 0 Wk & 20.53 & 6.06 & 22.50 & 5.03 \\
MVIC at 2 Wk & 23.83 & 6.94 & 23.86 & 5.11 \\
MVIC at 4 Wk & 26.50 & 6.74 & 24.56 & 5.09 \\
\hline
\end{tabular}

Unpaired t test for each variable among the two groups showed significant differences in the means $(\mathrm{P}>0.05)$. Mean differences in the Vertical Jump Height (VJH) compared at zero week and 4 week in the two groups were found to be significant with a value of $\mathrm{P}<0.007$ with Group-A with a value of $3.56 \pm 1.066$ and Group-B with a value of $2.27 \pm 0.814$. Thus VJH improved with High Intensity Plyometric exercises in Group A.

Maximum Voluntary Isometric Contraction (MVIC) when compared between 0 and 4 week showed a significant difference. Thus the values show that MVIC had a significant value at 0-4 week interval of time when Groups A and $\mathrm{B}$ were compared.

Paired $t$ test showed the result that all the values were significant $(\mathrm{P} \leq 0.05)$ when the test was applied separately within each group A and $\mathrm{B}$. The $\mathrm{t}$ value (probability) for VJH 0-2 week; 0-4 week and 2-4 week of Group A were - 8.184 (P $<0.000) ;-8.113(\mathrm{P}<0.000)$ and -10.557 $(\mathrm{P}<0.000)$ and for Group B were -5.016 $(\mathrm{P}<0.001) ;-7.224(\mathrm{P}<0.000)$ and -7.595 $(\mathrm{P}<0.000)$ respectively.

The $\mathrm{t}$ value for MVIC 0-2week; 0-4 week and 2-4 week of Group B were -
$7.487(\mathrm{P}<0.000) ;-0.270(\mathrm{P}<0.049)$ and $-6.760(\mathrm{P}<0.000)$ respectively. Thus all values of paired $t$ test show a significant change in the variables with plyometric training.

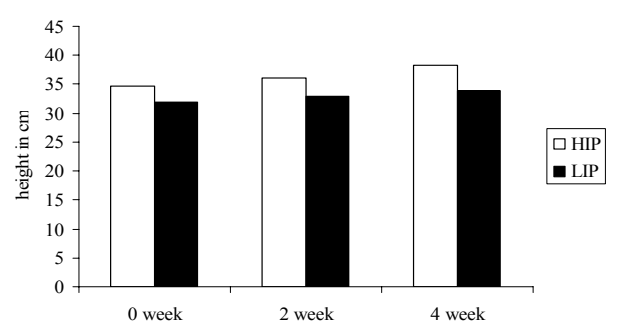

Fig. 1: Comparision of VJH of group $A$ and $B$ at 0 week, 2 week and 4 week

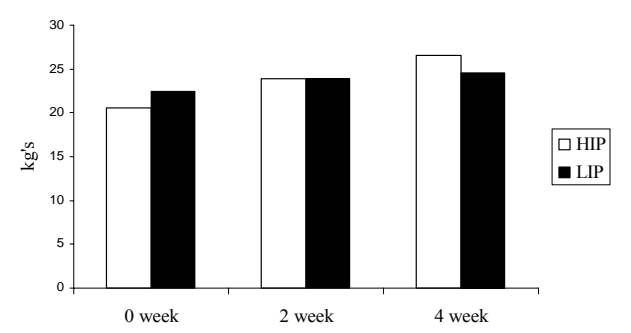

Fig. 2: Comparision of MVIC of group A and B at 0, 2 and 4 week

\section{Discussion}

This is an experimental study which compares the improvement in vertical jump height and maximal voluntary isometric contraction after high intensity plyometric and low intensity plyometric exercises in football players. The study is homogenous in nature as vertical jump height and maximal voluntary isometric contraction for both groups showed non-significant difference at the beginning of training. The results show a significant difference in vertical jump height and maximal voluntary isometric contraction following high intensity plyometric and low intensity plyometric exercises administered to the two groups of football players for a period of 4 weeks. At the same time, vertical 
jump height and maximal voluntary isometric contraction increased in both the groups proving the efficacy of plyometric exercise. These results supported the finding of previous researches concerning the elastic loading of muscle.

The results of this study indicating improvement in vertical jump height and maximal voluntary isometric contraction in the two groups are in agreement with the similar findings reported by Matavulj et al (2001); Toumi et al (2004); Wisloff et al (2004); Hoffman et al (2005) and McMillan et al (2005). In the present study, high intensity plyometric and low intensity plyometric exercises of four weeks showed different magnitudes of improvement in vertical jump height and maximal voluntary isometric contraction. Power is the ability to produce muscular forces very rapidly and is therefore very important in the game like football. Plyometric exercises are specialized exercises that enable a muscle to reach maximal strength in the shortest space of time. This works by stretching a muscle and then relying on its elastic properties to produce greater forces than are normally possible in the reflex contraction (as the muscle returns to it's resting length). In order to achieve this greater muscular force, the muscle must contract with in the shortest possible time following lengthening (www.playtheball.com). High intensity plyometric training administered to Group A produced more improvement in vertical jump height and maximal voluntary isometric contraction as compared to Low intensity plyometric training.

It can be speculated that improvements were a result of enhanced motor unit recruitment patterns as suggested by Potteiger et al (1999). Another possible reason can be neural adaptation which can occur when athletes respond or react as a result of improved co-ordination between the CNS signal and proprioceptive feedback as mentioned by Craig (2004). However, the important action of shock absorption or spring like action cannot be forgotten. This eccentric - concentric coupling is also referred to as stretch shortening cycle. Several authors have shown that an eccentric contraction immediately preceding a concentric contraction will significantly increase the force generated concentrically due to storage of elastic energy.

Donald Chu considers plyometrics to be among the best that can improve speed, strength, acceleration and explosive power allowing him or her to remain at the cutting edge of their sport (www.physioroom.com). The study shows increase in vertical jump height that can be explained well with an example of a "dig" just prior to vertical jump. By lowering the centre of gravity quickly, the muscles involved in the jump are momentarily stretched producing more powerful movements. This phenomenon can be explained on the basis of two models, Mechanical model postulated by Bosco et al (1982a) which says that the stored energy during eccentric contraction is released when the stretch is followed immediately by a concentric muscle action. According to Hill, the effect is like that of stretching a spring which wants to return to its natural length. The spring in this case is a component of muscle and tendon called the series elastic component (Hill, 1970). The second theory is based on a neurophysiological model (Gyton and Hall, 1995), which explains the 
stretch reflex. The stretch reflex increases the activity in the muscle undergoing the stretch or eccentric muscle action, allowing it to act much more forcefully. The result is a powerful braking effect on the potential for a powerful concentric muscle action (Bosco et al, 1982b). The ability to use the stored elastic energy is affected by three variables - time, magnitude of stretch and velocity of stretch. The quick change in direction is the important factor when using the elastic component of the muscle (Roper, 1998).

Not much effect has been seen of low intensity plyometric as compared with high intensity plyometric. According to a new study from Greece low intensity exercise is best for overall weight loss, while high intensity exercise is best for maintaining muscle mass ( $w w w$. bodycomposition.com).

It is well documented that vertical jump height and maximum voluntary isometric contraction are assessment tools for anaerobic energy system. Football is one of the sports in which anaerobic energy is also utilized along with aerobic and ATP-CP. Thus as vertical jump height and maximum voluntary isometric contraction show an improvement with the low intensity and high intensity plyometric exercises, it gives an indication of improvement of the anaerobic system of the athlete. Any increase in the anaerobic energy system helps in increasing the football players prformance. Thus choice can be made by coaches, athletes or physiotherapists between high intensity plyometric and low intensity plyometric for a sport specific activity. The results indicate towards the more acceptance of high intensity exercises to gain the improvement in vertical jump height and maximal voluntary isometric contraction. Low intensity exercises can be used effectively in increasing the anaerobic system of the athlete also.

\section{Conclusion}

Results of the study show that High Intensity Plyometric has significant effect on Vertical Jump Height and Maximum Voluntary Isometric Contraction as compared to Low Intensity Plyometric. Thus there is need to undergo High Intensity Plyometric if one wants to get the improvement in performance for competition.

\section{References}

Baechle, T.R., Earle, R.W. 2000. Essentials of strength training and conditioning. $2^{\text {nd }}$ edition. Champaign IL: National Strength and Conditioning Association.

Boissseau, N., Vermorei, M., Rance, M., Duche, P., Patureau-Mirand, P. 2007. Protein requirements in male adolescent soccer players. Eur, J. Appl. Physiol., 2.

Bosco, C., Ito, A., Komi, P.V., Luhtanen, P., Rahkila, P., Rusko, H., Vitasalo, J.T. 1982a. Neuromuscular function and mechanical efficiency of human leg extensor muscles during jumping exercises. Acta. Physiol. Scand. Apr; 114(4): 543-50.

Bosco, C., Komi, P.V., Viitasalo, J.T., Luhtanen, P. 1982b. Combined effect of elastic energy and myoelectrical potentiation during stretch shortening cycle exercise. Acta. Physiol. Scand., 114(4): 557-64.

Craig, B.W. 2004. What is the scientific basis of speed and agility? Strength and Conditioning,. 26(3): 13-14.

Gyton, A.C. and Hall, J.E. 1995. Textbook of Medical Physiology, 9th edition, Saunders, Philadelphia.

Hill, A.V. 1970. First and last experiments in muscle mechanics. Cambridge, University Press.

Hoffman, J.R., Ratamess, N.A., Cooper, J.J., Kang, J., Chilakos, A., Faigenbaum, A.D. 2005. Comparison of loaded and unloaded jump squat training on strength/power performance in college football players. J. Strength Cond. Res., 19(4): 810-815.

Kramer, J.F., Balsor, B.E. 1990. Lower extremity preference and knee extensor torques in 
intercollegiate soccer players. Can. J. Sports Sci., 15(3): 180-4.

Matavulj, D., Kukkolj, M., Ugarkovic, D., Tihanyi, J., Jaric, S. 2001. Effects of plyometric training on jumping performance in junior basketball players. J. Sports Med. Phys. Fitness, 41(2): 159-164.

Mcguigan, M..R., Doyle, T.L., Newton, M., Edwards, D.J., Nimphius, S., Newton, R.U. 2006. Eccentric utilization ratio: effect of sport and phase of training. J. Strength Cond. Res., 20(4): 992-5.

McMillan, K., Helgerud, J., Macdonald, R., Hoff, J., 2005. Physiological adaptations to soccer specific endurance training in professional youth soccer players. Br. J. Sports Med., 39(5): 273-7.

Moore, E.W., Hickey, M.S., Reiser, R.F. 2005 Comparision of two twelve week off-season combined training programs on entry level collegiate soccer player's performance. $J$. Strength Cond. Res., 19(4): 791-8.

Potteiger, J.A., Lockwood, R.H., Haub, M.D., Dolezal, B.A., Alumzaini, K.S., Schroeder, J.M. and Zebas, C.J. 1999. Muscle power and fiber characteristics following 8 weeks of plyometric training. J. Strength and Conditioning Research, (13): 275-279.
Roper, R.L. 1998. Incorporating agility training and backward movement into a plyometric program. Strength and Conditioning, 20(4): 60-63.

Siegler, J., Gaskill, S., Ruby, B. 2003. Changes evaluated in soccer-specific power endurance either with or without a 10 week, in season, intermittent, high intensity training protocol. J. Strength. Cond. Res., 17(2): 379-87.

Toumi, H., Best, T.M., Martin, A., F., Guyer, S., Poumarat, G. 2004. Effects of eccentric phase velocity of plyometric training on the vertical jump. Int. J Sports Med., 25(5): 391-398.

Williams, M. H. 1997. The Ergonomics Edge: Pushing the limits of sports performance. Human Kinetics.

Willifor, N.H., Kirpatrik, J. 1994. Physical performance characteristics of successful high school football players, Am. J. Sports Med., 22(6): 859-862.

Wisloff, U., Castagna, C., Helgerud, J., Jones, R., Hoff, J. 2004. Strong correlation of maximal squat strength with sprint performance and vertical jump height in elite soccer players. Br. $J$. Sports Med., 38(3): 285-288.

www. bodycomposition.com

www.physioroom.com

www.playtheball.com 